\title{
Does Biology Drive Child Penalties? Evidence from Biological and Adoptive Families
}

\author{
By Henrik Kleven, Camille Landais and Jakob Egholt Søgaard*
}

\begin{abstract}
This paper investigates if the impact of children on the labor market outcomes of women relative to men - child penalties - can be explained by the biological links between mother and child. We estimate child penalties in biological and adoptive families using event studies around the arrival of children and almost forty years of adoption data from Denmark. Short-run child penalties are slightly larger for biological mothers than for adoptive mothers, but their long-run child penalties are virtually identical and precisely estimated. This suggests that biology is not a key driver of child-related gender gaps.

JEL: D13, J13, J16, J22.
\end{abstract}

Parenthood has large and persistent effects on the labor market outcomes of women, but not men. This holds across different households, across different countries and over time, making it one of the most robust findings in labor economics. Estimates of long-run child penalties in female earnings range from $20-25 \%$ in Scandinavian countries to $30 \%$ in the United States and a staggering 60\% in Germany (Kleven, Landais and Søgaard 2019a; Kleven et al. 2019b). In fact, most of the remaining gender inequality in highincome countries can be attributed to the unequal impacts of children on men and women (Kleven, Landais and Søgaard 2019a; Kleven et al. 2020).

Why are child penalties so large and persistent? While the evidence on reduced-form impacts is fairly conclusive, our understanding of the underlying mechanisms is much less developed. A traditional explanation focuses on the factor that make men and women obviously different: biology. Only women can bear and give birth to children, and only women have the option to breastfeed. One would certainly expect such factors to matter for the short-run impacts of children, say within a year or two of child birth, but they could also matter for the long-run impacts.

Two sets of reasons point to the possibility of long-run impacts. First, the physiological implications of pregnancy, delivery and breastfeeding may extend beyond the short run. This could be due either to post-partum health complications or to changes in hormonal levels and brain structure around child birth. Indeed, a large literature in neurobiology argues that pregnancy and child birth create lasting changes in hormones and gray matter

\footnotetext{
* Kleven: Princeton University, NBER, CEPR, and CEBI, address1, kleven@princeton.edu. Landais: London School of Economics and CEPR, address2, c.landais@lse.ac.uk. Søgaard: University of Copenhagen and CEBI, address2, jes@econ.ku.dk. We thank Amy Finkelstein, Rohini Pande, and three anonymous referees for comments. We gratefully acknowledge support from the Center for Economic Behavior and Inequality (CEBI) at the University of Copenhagen, financed by grant \#DNRF134 from the Danish National Research Foundation. Søgaard also acknowledges support from the Marie Skłodowska-Curie Fellowship \#841969.
} 
associated with maternal attachment (see e.g., Numan and Insel 2003; Feldman et al. 2007; Hoekzema et al. 2017). Second, biology may affect long-run labor market outcomes through the dynamic effects of work interruptions. Interrupting work around pregnancy and infant child care may affect future earnings capacity through experience effects (such as human capital accumulation or signaling), and it may change preferences over family vs career. Indeed, the push for earmarked paternity leave in several countries is predicated on the idea that such leave may strengthen the bond between father and child, with longer-run implications for the division of child care.

Testing for the importance of biology requires separating the effects of having a child from the effects of giving birth to a child. A natural way of obtaining this separation is to compare child penalties in biological and adoptive families. However, any such investigation faces two challenges. The first challenge is statistical power: The best estimates of child penalties are based on event studies around the arrival of children, which require large panel data sets with information on labor market outcomes and children. This requirement is harder to satisfy for adopted children, because relatively few families adopt and data sources often do not record adoptions. We deal with this challenge by using Danish administrative data that contain exhaustive information on adoptions over almost forty years. The second challenge is identification: Adoptive families are a selected subsample of the population, implying that any differences in child penalties between biological and adoptive mothers may reflect selection rather than biology. We deal with this challenge by matching on a rich set of observables, showing that the matched samples display parallel pre-trends in the event studies.

We find large and persistent effects of children on gender gaps in both biological and adoptive families. Women and men evolve in parallel until the arrival of their first child, whether by birth or by adoption, and then diverge sharply and persistently. The short-run impacts are slightly larger in biological families, but the long-run impacts are virtually identical. Ten years after birth, the child penalty in earnings is $17-18 \%$ in both biological and adoptive families. ${ }^{1}$ When investigating the underlying determinants of earnings participation, hours worked, and wage rates - we find that biological and adoptive families are similarly impacted in those dimensions too. These findings provide evidence against the importance of the biological link between mother and child for explaining the gendered impacts of children.

More broadly, our results have implications for understanding the impact of comparative advantage in child care on gender gaps. Pregnancy and breastfeeding are the most obvious sources of such comparative advantage, and if these factors have no impact on long-run child penalties, it is conceivable that other sources of comparative advantage have no impact on child penalties either. ${ }^{2}$ To further investigate the role of comparative advantage, we

\footnotetext{
${ }^{1}$ The long-run child penalties estimated here are slightly smaller than those estimated in Kleven, Landais and Søgaard (2019a) for the full population. This is because we are reweighting biological families to match the characteristics of adoptive families, where the latter tend to have fewer children overall and therefore smaller child penalties.

${ }^{2}$ Women may have other biological sources of comparative advantage in child care than pregnancy and breastfeeding. This includes the argument among some biologists and psychologists that the female brain is hard-wired
} 
study heterogeneity in child penalties by the earnings potential of mothers relative to fathers in biological and adoptive families. The earnings potential is estimated based on detailed information about education level, education field, and labor market experience at the time of birth of the first child. Strikingly, we find that long-run child penalties are virtually unaffected by the relative earnings potential of women and men, and this holds in both biological and adoptive families. These findings suggest against the comparative advantage channel, and they are consistent with finding a zero effect of biological links between mother and child.

Our paper contributes to a large literature on gender inequality in the labor market (recently reviewed by Bertrand 2011 and Olivetti and Petrongolo 2016) and specifically to studies investigating the importance of parenthood (e.g., Bertrand, Goldin and Katz 2010; Angelov, Johansson and Lindahl 2016; Kleven and Landais 2017; Kleven, Landais and Søgaard 2019a; Kleven et al. 2019b; Kuziemko et al. 2018). Moreover, our finding that biological and adoptive mothers experience the same long-run child penalties - even though adoptees arrive later and require less maternity leave — sheds light on a key finding in the literature on parental leave policies (reviewed by Olivetti and Petrongolo 2017). This literature finds that paid leave has no long-term impact on female labor market outcomes and gender gaps (e.g., Lalive and Zweimüller 2009; Rossin-Slater, Ruhm and Waldfogel 2013; Lalive et al. 2014; Schönberg and Ludsteck 2014; Dahl et al. 2016). Our paper is consistent with this finding and go one step further: It suggests that we should expect limited long-term effects on maternal labor market outcomes from any policy or treatment that affects new mothers only temporarily, say in the first year or two following child birth.

Finally, our paper is related to Andresen and Nix (2019) who study child penalties in lesbian couples, where one partner is biologically linked to the child while the other partner is not. ${ }^{3}$ They find no long-term differences in child penalties between the biological mother and the "co-mother". In other words, biological links do not matter in couples where gender is held constant. An important advantage of studying adoptive couples over samesex couples is that it gives a much larger and less selected sample of the population, yielding more precision and greater generalizability. ${ }^{4}$

predominantly for empathy (conducive to care taking) while the male brain is hard-wired predominantly for understanding and building systems (see e.g., Baron-Cohen 2005).

${ }^{3}$ Related, Rosenbaum (2019) studies child penalties in lesbian couples who adopt.

${ }^{4}$ Regarding the selection argument, an important way in which same-sex parents differ from heterosexual parents is that their child penalty (for the biological mother as well as the co-mother) converges to zero in the long run. This stands in sharp contrast to the large long-run child penalties observed for heterosexual parents, whether biological or adoptive. 


\section{Empirical Specification and Data}

\section{A. Event Study Specification}

We estimate the impact of biological and adopted children on the labor market outcomes of men and women using the event study approach of Kleven, Landais and Søgaard (2019a). Specifically, we consider a balanced panel of parents observed in each year from 5 years before the arrival of their first child, by birth or by adoption, until 10 years after. We consider the following specification

$$
Y_{i t}=\boldsymbol{\alpha}^{\prime} \boldsymbol{D}_{i t}^{\text {Event }}+\boldsymbol{\beta}^{\prime} \boldsymbol{D}_{i t}^{A g e}+\boldsymbol{\gamma}^{\prime} \boldsymbol{D}_{i t}^{Y e a r}+\nu_{i t},
$$

where $Y_{i t}$ is the outcome (e.g., earnings) of individual $i$ at event time $t$. On the righthand side, we use boldface to denote vectors. The first term includes event time dummies, indexed such that $t=0$ denotes the year of arrival of the first child. We omit the dummy for $t=-1$, so that each $\alpha_{t} \in \boldsymbol{\alpha}$ measures the impact of children in a given year relative to the year before child arrival. The second and third terms include a full set of age and year dummies to control non-parametrically for lifecycle trends and time trends. ${ }^{5}$ This specification is run separately for men and women, and for those with biological and adopted children.

Equation (1) is specified in levels rather than logs to keep observations with zero earnings and thus capture both intensive and extensive margin responses. We convert level effects into percentage effects by calculating

$$
P_{t} \equiv \frac{\hat{\alpha}_{t}}{\mathrm{E}\left[\tilde{Y}_{i t} \mid t\right]},
$$

where $\tilde{Y}_{i t}$ is the predicted outcome when omitting the contribution of the event dummies. By running the estimations separately for men and women with biological and adopted children, we obtain four series of $P_{t}$. These series can be compared to estimate the impact of children on women relative to men - child penalties - in biological vs adoptive families across event time. This will shed light on the potential role of biology for short-run and long-run child penalties.

It is worth discussing two points on interpretation. First, differences in child penalties between biological and adoptive parents may not necessarily reflect biology alone, but also the differential selection of the two sets of parents. As we show, adoptive families tend to have their first child later, have fewer children overall, and have higher education and earnings levels. We deal with such selection issues by reweighting the sample of biological parents to ensure that their distribution of background characteristics $\left(x_{B}\right)$ exactly matches the distribution for the adoptive parents $\left(x_{A}\right)$. Formally, we compute weights as the relative

\footnotetext{
${ }^{5}$ The conditions for causal identification of the short- and long-term impacts of children in this framework are laid out and validated in Kleven, Landais and Søgaard (2019a).
} 
fraction of individuals with a certain set of characteristics in the two samples $\left(f\left(x_{A}\right) / f\left(x_{B}\right)\right)$ and use these weights in the regression (1) and in the expectation in equation (2) for the biological sample. By reweighting only the biological sample, we are able to adjust for a potentially rich set of observables while losing power only in the power-abundant biological sample.

Our baseline specification reweights the biological sample to match the distribution of the adoptive sample on the following variables: (i) year of arrival of the first child, (ii) years to arrival of the second child, (iii) the total number of children, (iv) the mother's age at first child, (v) the mother's pre-child education, and (vi) the mother's pre-child earnings. The first three variables (related to the timing and total number of children) ensures that biological and adoptive families experience the same treatment intensity. This is potentially important because, even though the event studies are centered on the arrival of the first child, the longer-run impacts will capture the impact of subsequent children as well. Hence, finding that biological and adoptive families experience similar long-run child penalties would not be very informative if they were treated differently by subsequent children. In robustness checks discussed below, we consider the implications of more parsimonious weighting schemes. ${ }^{6}$

Second, since adopted children do not arrive immediately after birth, there is a difference between event studies centered on child arrivals and event studies centered on child births. Our baseline specification is based on arrivals - the actual "event" for adoptive families - but a specification based on births would have merit as well. In particular, centering on births ensures that biological and adopted children have the same age at each event time, while centering on arrivals implies that adoptees are a little older (about one year older on average) at each event time. We consider specifications based on births in the online appendix, showing that the long-run child penalties are virtually the same when doing this.

\section{B. Data}

Our analysis uses administrative data from Statistics Denmark (DST) covering the full population between 1980 and 2017 (Statistics Denmark 2019a,b,c,d,e,f,g,h). The DST data combine several administrative registers linked at the individual level through personal identification numbers. The data allow us to link individuals to their family members and contain detailed information on earnings, labor supply, education, children, and a range of other variables.

We focus on the impact of foreign adoptions throughout. Domestic adoptions are less common, the children tend to be older at arrival, and the adoptive parents often have a preexisting link to the child (such as a step parent or aunt/uncle). Importantly, the adoption registry of Statistics Denmark only covers the period 1988-2009. Using this data alone would narrow the time window available for our event studies and reduce statistical power.

\footnotetext{
${ }^{6}$ Matching on variables determined after the arrival of the first child (years to second child and the total number of children) may pose threats to identification if these variables respond endogenously to the labor market impacts of the first child. We therefore consider specifications that match only on pre-child outcomes, showing that the estimates are very similar.
} 
We therefore augment the official records by identifying foreign adoptions outside the 19882009 window using information on country of origin and migration history. Specifically, we define foreign adoptees as individuals who fulfill the following conditions: (1) They were born in a non-western country, (2) they have two known parents born in a western country, (3) both parents had their legal address in Denmark (with no emigration record) at the time the child was born, and (4) the child has a recorded entry (immigration record) into the Danish Central Person Register after the date of birth.

To validate this procedure, Figure A.I in the online appendix compares our measure of adoptions to the official records during the time period where we have both. The figure shows that our measure captures the official numbers almost perfectly. Virtually all of our adoptees are also listed in the official records (no type II errors) and virtually no adoptees in the official records are missed by our measure (no type I errors). We find around 400-600 adoptions per year, corresponding to 16,260 children between 1980-2017. About two-thirds of all foreign adoptees come from Asia, and about $40 \%$ of the Asian adoptees come from South Korea. ${ }^{7}$

We focus on parents whose first child arrives (by birth or by adoption) between 1985 and 2007, which gives us data for at least 5 years before and 10 years after parenthood in all families. We require that both parents are known, alive and reside in Denmark in each year of the event time window $(t=-5, \ldots,+10)$. We impose no restrictions on the relationship status of the parents, including parents who are married, cohabiting, separated, divorced, or have not yet formed a couple in a given year. We also require that all subsequent children are of the same type as the first (adopted or biological) such that we are comparing purely biological to purely adoptive families, and we restrict attention to adoptive children arriving before the age of 5 . These data restrictions leave us with around 527,000 first births in the biological sample and around 4,600 first arrivals in the adoptive sample. ${ }^{8}$

Our main outcome of interest is annual earnings. This includes income from wages, salaries, and self-employment. We also consider the impact of children on labor force participation, hours worked, and wage rates (earnings/hours worked). Our measures of hours worked and wage rates are based on administrative and third-party reported data from a mandated pension scheme called Arbejdsmarkedets Tillagspension (ATP), which requires employers to contribute on behalf of their employees based on individual hours worked.

Table 1 provides descriptive statistics in three samples: adoptive families, biological families, and reweighted biological families. While other studies (e.g., Fagereng, Mogstad and Rønning 2019) have shown that foreign adoptees are as good as randomly allocated to adoptive families, our table shows that adoptive families are a selected subsample of the population. For example, adoptive parents tend to have their first child later, have fewer children in total, and have higher education and earnings than biological parents. This motivates our reweighting procedure described above. As shown in the table, this procedure ensures that the distribution of adoptive and biological families are balanced

\footnotetext{
${ }^{7}$ See Table A.I in the online appendix.

${ }^{8}$ See Table A.II in the online appendix.
} 
on year of first child, years to second child, total number of children, the mother's age at first child, and the mother's pre-child education and earnings levels. The adoptive and reweighted biological samples retain minor discrepancies on some of the matching variables, because we match on binned rather than continuous variables.

\section{Results}

\section{A. Child Penalties in Biological vs Adoptive Families}

Figure 1 shows the earnings impacts of parenthood on men and women in biological and adoptive families, respectively. Panel A considers all adoptees pooled, while Panel B considers adoptees split by their age at arrival. Each dot gives the percentage impact at event time $t$ (relative to event time -1) based on the specification in (1)-(2). As described above, this specification controls non-parametrically for any underlying lifecycle and time trends, and it is implemented on a reweighted biological sample.

Consider first biological families. Relative to the underlying life-cycle and time trends, the earnings of men and women evolve in parallel until child birth and then diverge sharply. Female earnings drop by about $25 \%$ immediately after child birth, while male earnings are unaffected. Women recover some of their earnings loss after infant child care, but they never catch back up to men. The figure shows the implied long-run child penalty, defined as the average difference in the impact of children $\left(P_{t}\right.$ in equation 2$)$ between men and women across event times 6-10. The long-run child penalty in biological families is equal to $17.0 \%$. These findings are well-known and hold across different countries (Kleven, Landais and Søgaard 2019a; Kleven et al. 2019b). ${ }^{9}$

Consider then adoptive families. The main insight from Panel A of Figure 1 is that adoptive families are affected by parenthood in much the same way as biological families. The earnings of adoptive parents evolve in parallel before having children and then diverge sharply and persistently after having children. The short-run earnings impacts are somewhat smaller in adoptive families than in biological families, but the long-run impacts are virtually the same. The long-run child penalty on adoptive mothers equals $18.1 \%$ and is statistically indistinguishable from the penalty of $17.0 \%$ on biological mothers. That is, even though adoptive mothers are not biologically linked to their children and are unaffected by aspects such as breastfeeding and postpartum health complications, they converge to long-run penalties at least as large as those for biological mothers.

Furthermore, the penalties on adoptive mothers feature little heterogeneity by their child's age at arrival as shown in Panel B. The different adoptive subsamples - those with early, intermediate, and late arrivals - line up closely throughout the event study window. Even adoptive mothers whose first child arrives after the age of one (two) experience a longrun penalty of $17.9 \%(16.7 \%)$, statistically indistinguishable from the penalty of $17.0 \%$ on

\footnotetext{
${ }^{9}$ The long-run child penalty of $17.0 \%$ estimated here is slightly smaller than the penalty of $19.4 \%$ estimated in Kleven, Landais and Søgaard (2019a). This is due to the fact that biological families have been reweighted to match adoptive families.
} 
biological mothers. In other words, the age of the child is not critical for the labor market impacts, at least not after the initial stage of breastfeeding and infant child care. ${ }^{10}$

As discussed in Section I, our baseline specification reweights the biological sample to match the adoptive sample in terms of the number and timing of children as well as the mother's education and earnings levels prior to having children. Figure A.III in the online appendix investigates robustness to alternative weighting schemes. Without any reweighting (Panel A), the long-run child penalty is 3.4pp larger in biological families than in adoptive families. Matching the samples on some observables is therefore important for the conclusion that biology does not affect long-run penalties. Reweighting only on prebirth variables (Panel B) avoids any concerns about the potential endogeneity of fertility decisions made after the first child. Reassuringly, this specification yields very similar results as the baseline specification (repeated in Panel $\mathrm{C}$ of the figure). ${ }^{11}$

\section{B. Anatomy of Child Penalties}

In this section we investigate the anatomy of the large and persistent earnings impacts of both biological and adopted children. Figure 2 presents event studies of the three underlying earnings determinants: hours worked conditional on working (Panel A), the labor force participation rate (Panel B), and the wage rate (Panel $\mathrm{C}$ ).

For hours worked and the wage rate, we find virtually identical child penalties in biological and adoptive families throughout the event study window. The long-run hours penalty is about $7 \%$ and the wage rate penalty is about $10 \%$ in both family types. The participation penalty, on the other hand, is larger in biological families than in adoptive families during the initial years of parenthood. But the two family types converge to the same level over time, a long-run participation penalty of around 3-4\%. Taken together, these findings imply that the short-lived differences in earnings penalties documented in the previous section can be explained by differences in extensive margin responses that last for 3-4 years and then dissipate. The short-run differences in extensive margin responses are likely driven by the larger need for maternity leave among biological mothers due to aspects like breastfeeding and health complications.

Table 2 summarizes the graphical results presented so far. The table shows estimates of child penalties in different labor market outcomes (earnings, hours, participation, and wage rates) in biological and adoptive families. Panel A focuses on the short run (event times 0-5), while Panel B focuses on the long run (event times 6-10). The short-run earnings penalty is 3.7 percentage points larger in biological families than in adoptive families and

\footnotetext{
${ }^{10}$ In Figure A.II in the online appendix, we replicate the analysis presented here when centering on child births instead of child arrivals. In this case, the short-run differences between biological and adoptive families are larger due to the delayed arrival of adoptees. When splitting adoptees by their age at arrival, the short-run impacts are staggered across ages as one would expect. Despite these short-run differences, however, the long-run impacts on biological and adoptive families are still very similar (and they are similar to those estimated when centering the analysis on arrivals in Figure 1).

${ }^{11}$ All of the matching variables that we retain in the more parsimonious specification in Panel B (year of first child, mother's age at first child, and mother's pre-child education and earnings) do matter for our conclusions. For example, if we do not match on pre-child education and earnings, the short-run differences between biological and adoptive mothers become larger and there are some long-run differences as well.
} 
this difference is statistically significant. Looking at the underlying drivers of the difference in earnings impacts, only the difference in participation impacts is statistically significant. Turning to the long run, the differences in child penalties between biological and adoptive mothers are small and statistically insignificant for all four outcomes. The differences are precisely estimated, allowing us to rule out any economically significant impact of biology on observed child penalties.

\section{Heterogeneity in Child Penalties by Comparative Advantage}

A classic explanation for the large and persistent child penalties on women focuses on specialization based on comparative advantage: women have a comparative advantage in child care, while men have a comparative advantage in market work. Our results have implications for this interpretation. The most obvious reason why women would have a comparative advantage in child care is based on the biological link between mother and child. The fact that only women can bear children and breastfeed almost certainly gives them a comparative advantage in the early stages of parenthood, and it may give rise to longer-lasting comparative advantage due to changes in earnings capacity and preferences. The absence of persistent differences in child penalties between biological and adoptive mothers run counter to these ideas. However, it is possible that comparative advantage is important, but that the source of comparative advantage studied here (the biological link between mother and child) is short-lived, while other sources of comparative advantage are longer-lived. To investigate this point, this section presents evidence on heterogeneity in child penalties by comparative advantage.

Studying the role of comparative advantage requires a measure of male and female earnings capacity within families. To avoid endogeneity of measured earnings capacity to children, one strategy would be to divide the sample by observed earnings prior to the arrival of children. However, selecting subsamples based on pre-child earnings may create problems with mean reversion: If earnings consist of both permanent and transitory income components, we would be splitting the sample partly by transitory income shocks rather than by comparative advantage alone. To avoid such problems, we use potential earnings rather than actual earnings to measure comparative advantage.

We estimate potential earnings based on Mincer regressions of earnings on education level and experience within cells of education field. Dividing the sample into 140 different education fields (such as "physics" or "acting"), we run the following regression within each field

$$
\ln Y_{i s}=\alpha E d u_{i s}+\beta_{1} \operatorname{Exp}_{i s}+\beta_{2} \operatorname{Exp}_{i s}^{2}+\gamma Y e a r_{s}+\nu_{i s}
$$

where $Y_{i s}$ is earnings of individual $i$ in year $s, E d u_{i s}$ is a set of education dummies (six levels from elementary school to $\mathrm{PhD}$ ), Exp $p_{i s}$ is experience (years since graduation), and $Y_{e a r}$ is a set of year dummies. These regressions are run on the sample of men alone (as they are unaffected by children), using the estimated coefficients to predict potential earnings for both men and women. We then split the sample by relative female earnings 
potential within families prior to the arrival of the first child (at event time -1).

The results are shown in Figure 3. The figure shows earnings impacts in both biological and adoptive families, split by relative female earnings potential. Panel A compares families below and above the median of the distribution of relative female earnings potential, while Panel B compares families in the bottom and top quartiles of that distribution. The difference in comparative advantage is sizeable in these sample cuts: Women in the top quartile (half) of relative female earnings potential contribute $61 \%(57 \%)$ of the total household earnings potential, whereas women in the bottom quartile (half) contribute only $38 \%(42 \%)$. If comparative advantage matters, we should see larger child penalties in families where the woman's relative earnings potential is lower. Instead we see that child penalties are unrelated to our proxy for comparative advantage: the long-run child penalties are very similar for low-earning and high-earning mothers, and this holds in both biological and adoptive families. ${ }^{12}$ This suggests against the importance of the comparative advantage channel and is consistent with our main finding that biology has no effect on child penalties.

\section{Conclusion}

A recent literature documents large child penalties in female labor market outcomes, showing that these penalties can explain most of the remaining gender inequality in developed countries (see e.g., Kleven, Landais and Søgaard 2019a; Kleven et al. 2019b). In this paper, we ask why the impacts of children are so large and gendered, focusing on traditional explanations rooted in biology and comparative advantage. Using Danish administrative data, we provide compelling event study evidence on child penalties in biological and adoptive families. Despite the existence of short-run differences in the child penalties of these two family types, they converge to the same penalty in the long run. This is true for earnings as well as for its underlying determinants.

Our findings provide evidence against the importance of biological links between mother and child for explaining child penalties. Moreover, since these biological links represent some of the most obvious sources of comparative advantage, they provide evidence against classic specialization stories. We provide further evidence on comparative advantage, showing that child penalties are unrelated to the relative earnings potential within families in both biological and adoptive families. Overall, this paper suggests that child-related gender inequality (i.e., most remaining gender inequality) cannot be understood through the lens of biology and incentive-based specialization, pushing towards a greater focus on preference formation, social norms and culture.

\section{REFERENCES}

Andresen, Martin Eckhoff, and Emily Nix. 2019. "What Causes the Child Penalty and How Can It Be Reduced? Evidence from Same-Sex Couples and Policy Reforms."

\footnotetext{
${ }^{12}$ Figure A.IV in the online appendix shows that this finding is robust to alternative measures of relative female earnings potential, including measures that are more forward-looking.
} 
Working Paper.

Angelov, Nikolay, Per Johansson, and Erica Lindahl. 2016. "Parenthood and the Gender Gap in Pay." Journal of Labor Economics, 34: 545-579.

Baron-Cohen, Simon. 2005. "The Essential Difference: The Male and Female Brain." Phi Kappa Phi Forum, 85(1): 23-26.

Bertrand, Marianne. 2011. "New Perspectives on Gender." In Handbook of Labor Economics. Vol. 4b, , ed. O. Ashenfelter and D. Card, Chapter 17, 1543-1590. North Holland: Elsevier Science Publishers.

Bertrand, Marianne, Claudia Goldin, and Lawrence F. Katz. 2010. "Dynamics of the Gender Gap for Young Professionals in the Financial and Corporate Sectors." American Economic Journal: Applied Economics, 2(3): 228-255.

Dahl, Gordon B., Katrine V. Løken, Magne Mogstad, and Kari Vea Salvanes. 2016. "What is the Case for Paid Maternity Leave?" Review of Economics and Statistics, 98(4): 655-670.

Fagereng, Andreas, Magne Mogstad, and Marte Rønning. 2019. "Why Do Wealthy Parents Have Wealthy Children?" Working Paper.

Feldman, Ruth, Aron Weller, Orna Zagoory-Sharon, and Ari Levine. 2007. "Evidence for a Neuroendocrinological Foundation of Human Affiliation: Plasma Oxytocin Levels Across Pregnancy and the Postpartum Period Predict Mother-Infant Bonding." Psychological Science, 18(11): 965-970.

Hoekzema, Elseline, Erika Barba-Müller, Cristina Pozzobon, Marisol Picado, Florencio Lucco, David García-García, Juan Carlos Soliva, Adolf Tobeña, Manuel Desco, Eveline A. Crone, Agustín Ballesteros, Susanna Carmona, and Oscar Vilarroya. 2017. "Pregnancy Leads to Long-Lasting Changes in Human Brain Structure." Nature Neuroscience, 20(2): 287-296.

Kleven, Henrik, and Camille Landais. 2017. "Gender Inequality and Economic Development: Fertility, Education, and Norms." Economica, 84: 180-209.

Kleven, Henrik, Camille Landais, and Jakob Egholt Søgaard. 2019a. "Children and Gender Inequality: Evidence from Denmark." American Economic Journal: Applied Economics, 11(4): 181-209.

Kleven, Henrik, Camille Landais, Johanna Posch, Andreas Steinhauer, and Josef Zweimüller. 2019b. "Child Penalties Across Countries: Evidence and Explanations." AEA Papers and Proceedings, 109: 122-126.

Kleven, Henrik, Camille Landais, Johanna Posch, Andreas Steinhauer, and Josef Zweimüller. 2020. "Do Family Policies Reduce Gender Inequality? Evidence from 60 Years of Policy Experimentation." Working Paper. 
Kuziemko, Ilyana, Jessica Pan, Jenny Shen, and Ebonya Washington. 2018. "The Mommy Effect: Do Women Anticipate the Employment Effects of Motherhood?" NBER Working Paper No. 24740.

Lalive, Rafael, Analía Schlosser, Andreas Steinhauer, and Josef Zweimüller. 2014. "Parental Leave and Mothers' Careers: The Relative Importance of Job Protection and Cash Benefits." The Review of Economic Studies, 81: 219-265.

Lalive, Rafael, and Josef Zweimüller. 2009. "How Does Parental Leave Affect Fertility and Return to Work? Evidence from Two Natural Experiments." The Quarterly Journal of Economics, 124(3): 1363-1402.

Numan, Michael, and Thomas R. Insel. 2003. The Neurobiology of Parental Behavior. Springer-Verlag New York.

Olivetti, Claudia, and Barbara Petrongolo. 2016. "The Evolution of Gender Gaps in Industrialized Countries." Annual Review of Economics, 8: 405-434.

Olivetti, Claudia, and Barbara Petrongolo. 2017. "The Economic Consequences of Family Policies: Lessons from a Century of Legislation in High-Income Countries." Journal of Economic Perspectives, 31(1): 205-230.

Rosenbaum, Philip. 2019. "The Family Earnings Gap Revisited: A Household or a Labor Market Problem?" Working Paper.

Rossin-Slater, Maya, Christopher J. Ruhm, and Jane Waldfogel. 2013. "The Effects of California's Paid Family Leave Program on Mothers' Leave-Taking and Subsequent Labor Market Outcomes." Journal of Policy Analysis and Management, 32(2): 224-245.

Schönberg, Uta, and Johannes Ludsteck. 2014. "Expansions in Maternity Leave Coverage and Mothers' Labor Market Outcomes after Childbirth." Journal of Labor Economics, 32(3): 469-505.

Statistics Denmark. 2019a. "Adoptioner (ADOP, Adoptions), 1980-2017 [database]." Research Service of Statistics Denmark.

Statistics Denmark. 2019b. "Befolkningen (BEF, Population), 1980-2017 [database]." Research Service of Statistics Denmark.

Statistics Denmark. 2019c. "Husstande og familier (FAIN, Households and Families), 1980-2017 [database]." Research Service of Statistics Denmark.

Statistics Denmark. 2019d. "IDAP Arbejdsmarkedsdata (IDAP, Labor Market Data), 1980-2017 [database]." Research Service of Statistics Denmark.

Statistics Denmark. 2019e. "Indkomst (IND, Income), 1980-2017 [database]." Research Service of Statistics Denmark. 
Statistics Denmark. 2019f. "RAS Arbejdsmarkedsdata (RAS, Labor Market Data), 1980-2017 [database]." Research Service of Statistics Denmark.

Statistics Denmark. 2019g. "Uddanelser (UDDA, Educations), 1980-2017 [database]." Research Service of Statistics Denmark.

Statistics Denmark. 2019h. "Vandringer (VNDS, Migrations), 1980-2017 [database]." Research Service of Statistics Denmark. 
Figure 1. : Child Penalties in Biological vs Adoptive Families

\section{A: All Adoptees}

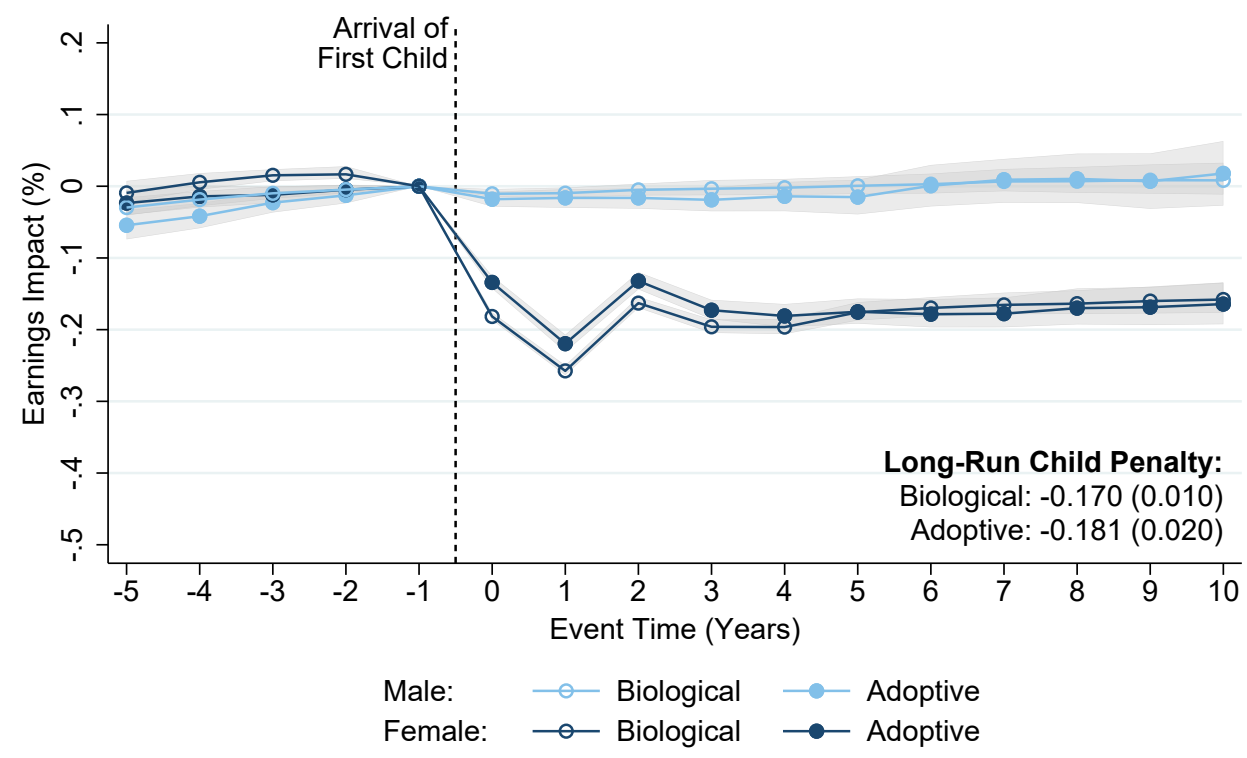

\section{B: Adoptees by Age at Arrival}

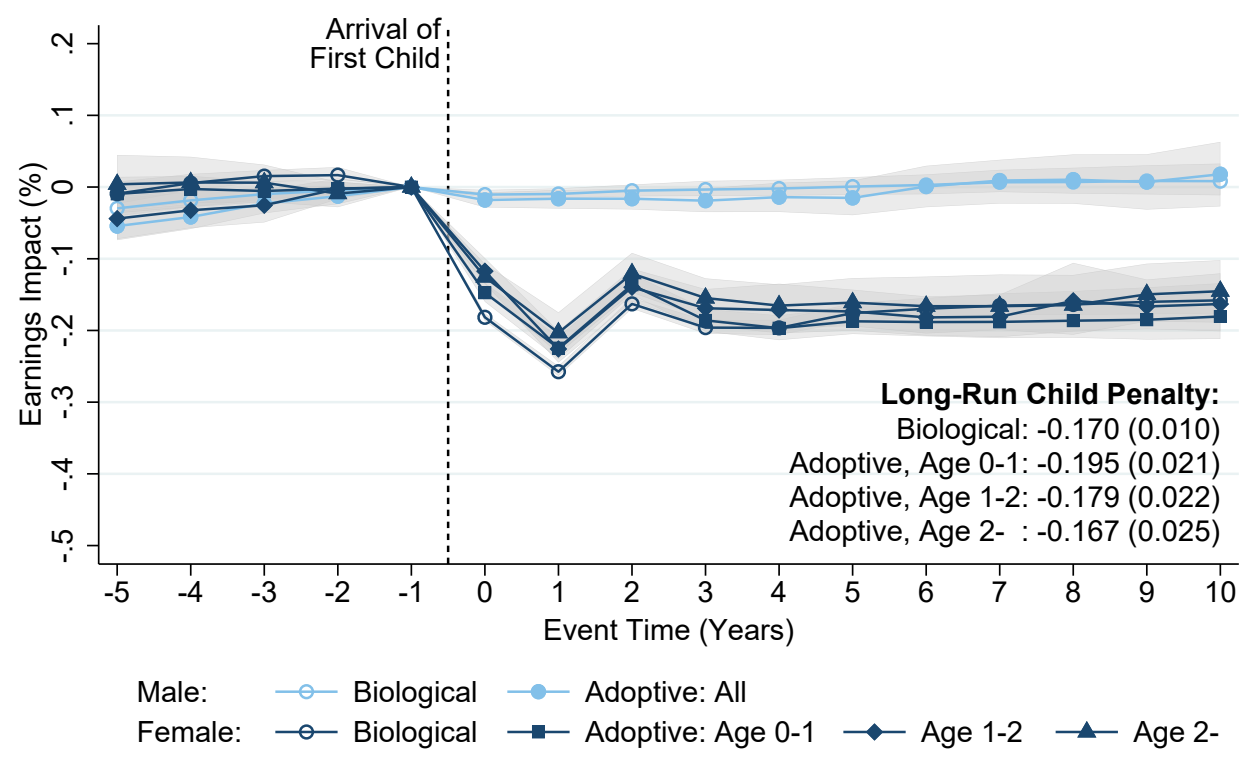

Note: The figure shows the impact of children ( $P_{t}$ defined in equation 2) on the earnings of men and women in biological and adoptive families, respectively. The sample of biological parents is reweighted to match the distribution of the adoptive parents on (i) year of first child, (ii) years to second child, (iii) total number of children, (iv) mother's age at first child, (v) mother's pre-child education, and (vi) mother's pre-child earnings. Panel A pools all adoptees, while Panel B splits adoptees by their age at arrival. The long-run child penalty is defined as the average difference in the impact of children between men and women across event times 6-10. Standard errors are bootstrapped (500 replications). 
Figure 2. : Anatomy of Child Penalties

\section{A: Hours Worked}

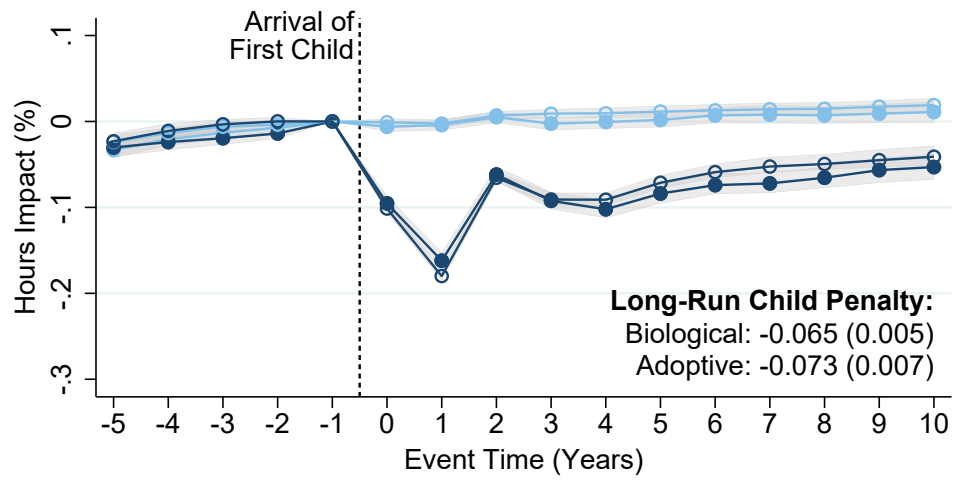

\section{B: Participation Rate}

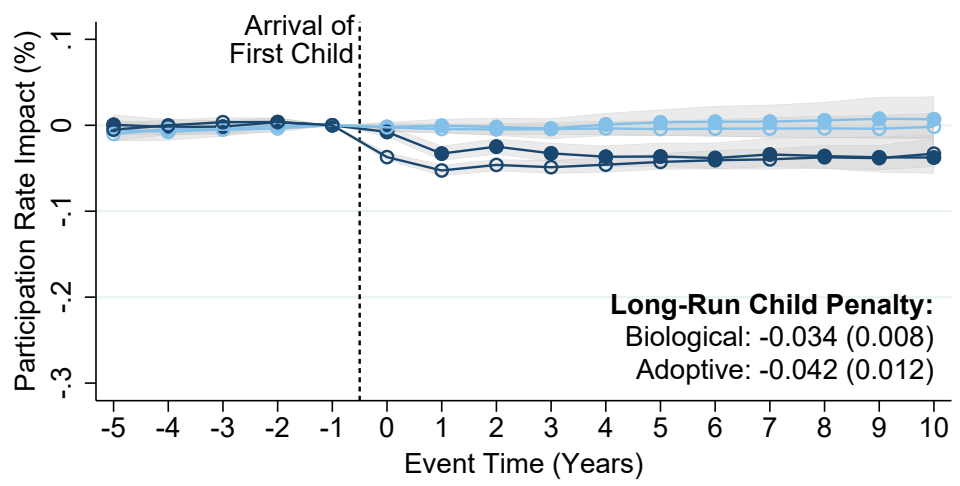

\section{C: Wage Rate}

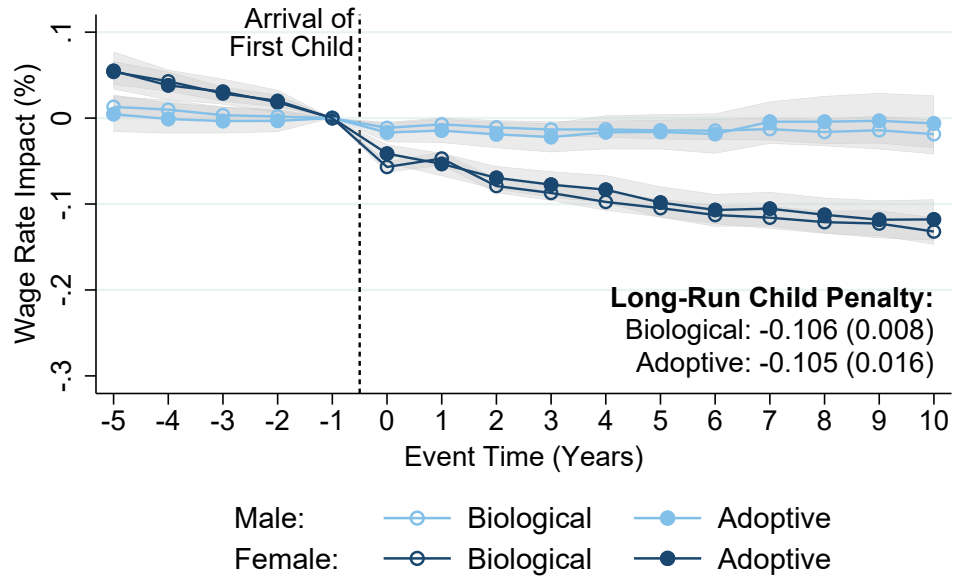

Note: The figure shows the impact of children $\left(P_{t}\right.$ defined in equation 2$)$ on the underlying determinants of earnings for men and women in biological and adoptive families, respectively. Panel A shows the impact on hours worked (conditional on working) using our ATP hours measure. Panel B shows the impact on participation (positive ATP hours). Panel $\mathrm{C}$ shows the impact on the wage rate (conditional on working), computed as annual earnings divided by annual ATP hours. We winsorize wage rates at 0 and the 99th percentile to deal with measurement error due to the fact that some workers (in particular, the self-employed) may have large positive or negative earnings with very small ATP hours. The figure is otherwise constructed as Panel A of Figure 1 and the sample of biological parents is reweighted in the same way. Standard errors are bootstrapped (500 replications). 
Figure 3. : Child Penalties by Relative Female Earnings Potential

\section{A: Bottom Half vs Top Half}

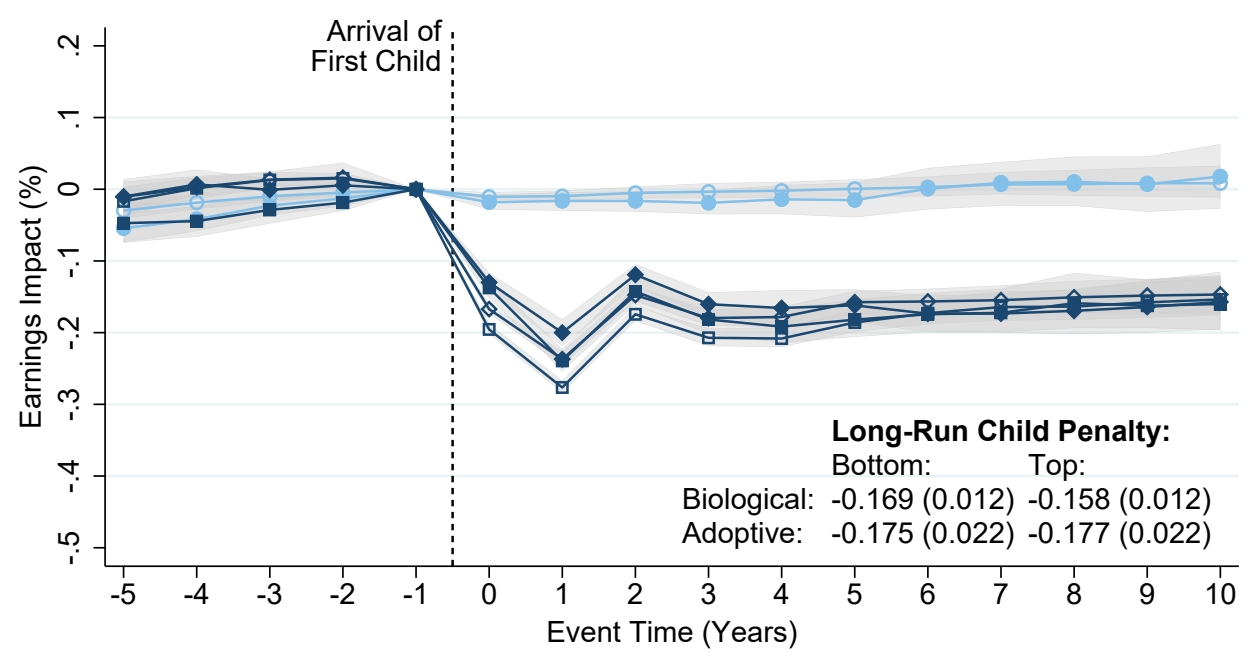

B: Bottom Quartile vs Top Quartile

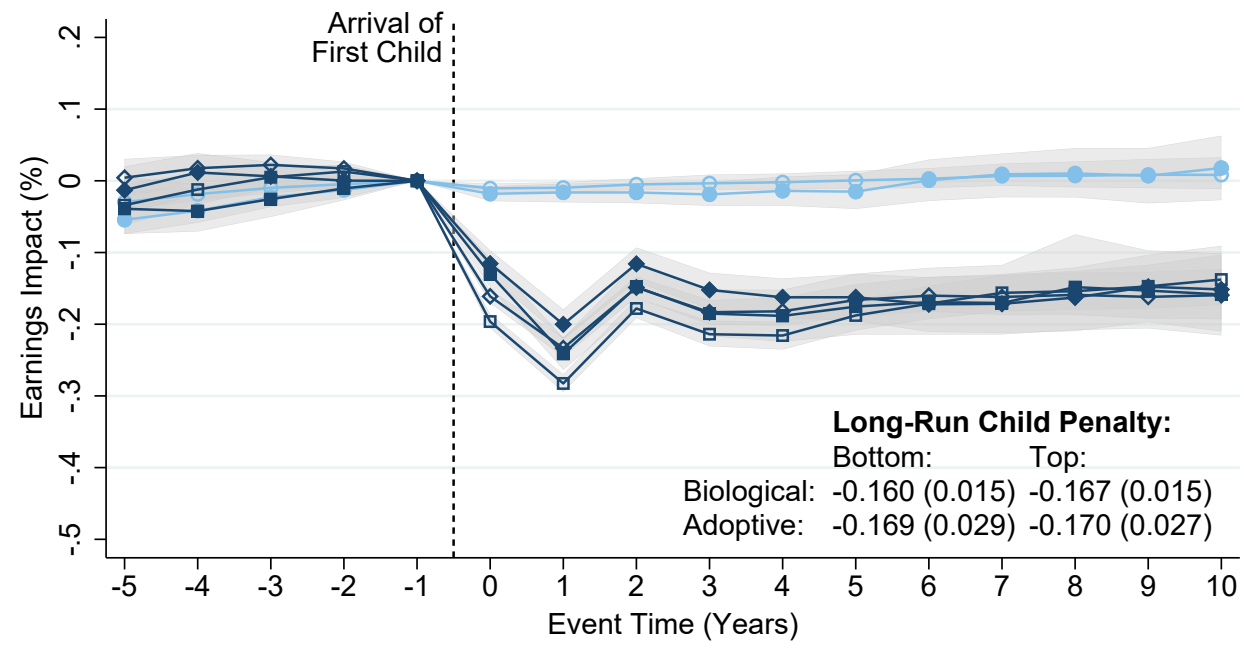

Biological: $\multimap$ Male $\multimap$ Female, Bottom $\multimap$ Female, Top
Adoptive: $\quad \longrightarrow$ Male $\rightarrow-$ Female, Bottom $\multimap$ Female, Top

Note: The figure is constructed in the same way as Figure 1 and shows the earnings impact of children on men and women in biological and adoptive families, respectively. To investigate the role of comparative advantage, the sample of women is split by relative female earnings potential within families prior to the arrival of children (at event time -1). The earnings potential of women and men is estimated based on Mincer regressions of earnings on education level and experience within cells of education field (as specified in eq. 3). Panel A compares women below and above the median of the distribution of relative female earnings potential, while Panel B compares women in the bottom and top quartiles of that distribution. These splits are done separately for biological and adoptive mothers, but the distributions of relative female earnings potential are very similar for the two samples. Standard errors are bootstrapped (500 replications). 


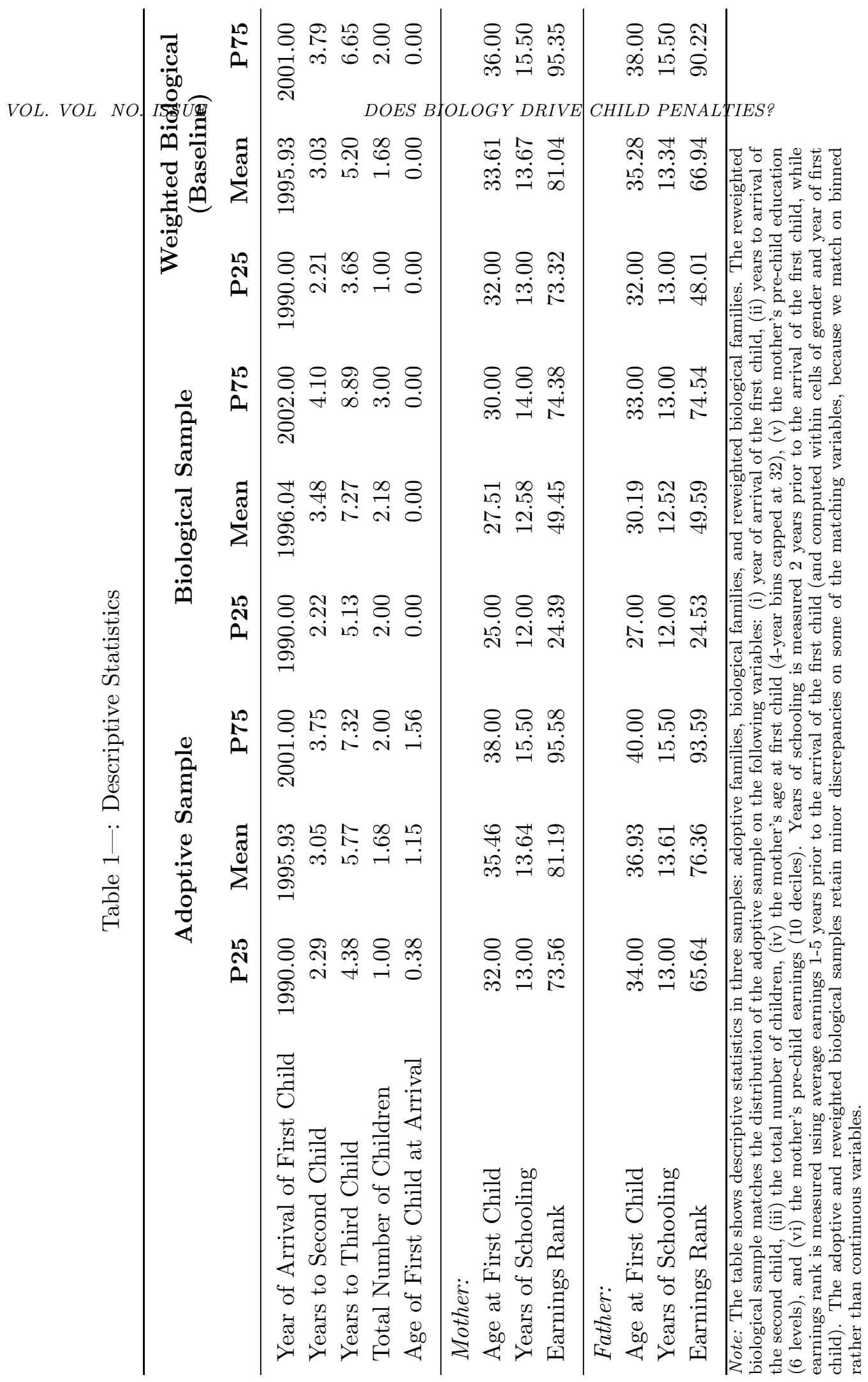


Table 2-: Child Penalties in Biological vs Adoptive Families

\begin{tabular}{lcccc}
\hline & Earnings & Hours & Participation & Wage Rate \\
\hline Panel A: Short Run & Event Times 0-5) & \\
\hline Biological & -0.190 & -0.106 & -0.042 & -0.067 \\
& $(0.005)$ & $(0.003)$ & $(0.004)$ & $(0.004)$ \\
Adoptive & -0.153 & -0.098 & -0.028 & -0.053 \\
& $(0.008)$ & $(0.004)$ & $(0.006)$ & $(0.008)$ \\
Difference & 0.037 & 0.007 & 0.014 & 0.014 \\
& $(0.009)$ & $(0.005)$ & $(0.007)$ & $(0.009)$ \\
\hline \multirow{2}{*}{ Panel B: Long Run (Event Times } & $\mathbf{6 - 1 0 )}$ & \\
\hline Biological & -0.170 & -0.065 & -0.034 & -0.106 \\
& $(0.010)$ & $(0.005)$ & $(0.008)$ & $(0.008)$ \\
Adoptive & -0.181 & -0.073 & -0.042 & -0.105 \\
& $(0.020)$ & $(0.007)$ & $(0.012)$ & $(0.016)$ \\
Difference & -0.011 & -0.008 & -0.008 & 0.001 \\
& $(0.022)$ & $(0.009)$ & $(0.013)$ & $(0.018)$ \\
\hline
\end{tabular}

Note: The table shows estimates of child penalties in biological and adoptive families for different labor market outcomes (earnings, hours, participation, and wage rates). Child penalties are defined as the impact of children for women relative to men $\left(P_{t}^{\text {women }}-P_{t}^{m e n}\right.$ where $P_{t}$ is defined in eq. 2). Panel A shows short-run penalties (an average across event times 0-5), while Panel B shows long-run penalties (an average across event times 6-10). Standard errors are bootstrapped (500 replications). 